\title{
Spatial differential conditioning of the nictitating membrane response in hippocampectomized rabbits
}

\author{
NEIL E. BERTHIER and JOHN W. MOORE \\ University of Massachusetts, Amherst, Massachusetts 01003
}

\begin{abstract}
Rabbits with bilateral aspiration lesions of the dorsal hippocampus were trained on a spatial differential conditioning task (nictitating membrane response) in which the offset of one of two panel lights was paired with the unconditioned stimulus (US). Offset of the second panel light was not paired with the US. Hippocampectomized rabbits $(n=9)$ were not impaired in comparison with partially neodecorticated $(n=5)$ and nonoperated $(n=6)$ controls. The results are discussed in relation to O'Keefe and Nadel's (1978) cognitive map theory of the hippocampus.
\end{abstract}

O'Keefe, Nadel, and Willner (1979) have extended the cognitive map theory of the hippocampus (e.g., O'Keefe \& Nadel, 1978) to classical conditioning:

According to cognitive map theory, there are three different ways that the hippocampus can be involved in learning and performance.

1. Learning about places: Organisms build maps of environments. An environment or specific places within it can be tagged as dangerous or as containing rewards such as food or water.

2. Strategies using places: Using its map, the animal can identify its position within the environment as well as the distance and direction to other places.

3. Attention to places: The mapping system can aid in learning about a stimulus in an environment either by directing the animal's attention to particular places in which that stimulus occurs or by assessing the stimulus as novel, that is, one that is not represented in the mapping system as occurring in that place in the environment (O'Keefe et al., 1979, p. 1282).

O'Keefe et al. (1979) have applied these principles to several phenomena, for example, stimulus preexposure effects as in latent inhibition, that have given rise to alternative interpretations of the role of the hippocampus in classical conditioning (Berger \& Thompson, 1978; Moore, 1979; Solomon, 1979; Solomon \& Moore, 1975).

A seemingly straightforward prediction of the cognitive map theory is that animals with hippocampal damage would have difficulty performing appropriately in a differential conditioning task in which the reinforced conditioned stimulus (CS+) differs from the nonreinforced conditioned stimulus (CS-) in spatial

This research was supported by NSF Grant BNS 77-14871. The authors are grateful to Paul R. Solomon for suggesting this experiment. Requests for reprints should be sent to John W. Moore, Middlesex House, University of Massachusetts, Amherst, Massachusetts 01003 . location. This expectation follows most directly from O'Keefe et al.'s (1979) Point 3: An intact hippocampus would aid in directing the animal's attention to the position of the CS+ in space, thus enabling it to give conditioned responses to that stimulus but not to an otherwise identical stimulus (CS-) located elsewhere.

Rabbits with bilateral ablations of the dorsal hippocampal formation, similar to those of Solomon and Moore (1975), were contrasted with nonoperated and partially neodecorticated rabbits in differential conditioning of the nictitating membrane response (NMR): $\mathrm{CS}+$ was the offset of one of two panel lights located in front of the animal; CS- was the offset of the other. To our knowledge, the present study represents the first investigation of simple differential NMR conditioning in hippocampal rabbits.

Light offset rather than onset was selected as the defining property of the CSs because it was thought that the illumination they provided would be necessary in order for the restrained animal to form a cognitive map of the test environment. Light offset also mitigated potential complications arising from dark adaptation over the 50-min duration of each session.

Each CS produced the same step decrease in the illumination of the test environment. Since dorsal hippocampal ablations do not impair conditioning of the rabbit NMR to a tone CS (e.g., Solomon \& Moore, 1975), it was expected, under cognitive map theory, that rabbits with hippocampal damage would acquire the conditioned response as though a single light were reduced in brightness and paired with the US on a $50 \%$ reinforcement schedule; that is, differential responding would be disrupted, if not eliminated altogether.

\section{METHOD}

Subjects

The subjects were 20 previously conditioned adult New Zealand 
rabbits maintained on ad-lib food and water. They were caged individually under continuous illumination of the colony room.

\section{Surgery and Histology}

Under pentobarbital anesthesia $(50 \mathrm{mg} / \mathrm{kg}$, iv), bilateral aspiration of the dorsal hippocampal formation, or overlying neocortex, was performed as described elsewhere (e.g., Solomon \& Moore, 1975). Recovery times prior to differential conditioning ranged from 4 to 6 weeks.

Following differential conditioning, operated animals were deeply anesthetized with sodium pentobarbital, their brains perfused by intracardial infusion of $.9 \%$ saline followed by $10 \%$ Formalin solution, and then removed, stored in Formalin, and subsequently embedded in $20 \%$ gelatin. Coronal sections of $40 \mu$ were stained with $.5 \%$ cresyl violet for histological examination.

\section{Apparatus and Procedure}

The apparatus and procedures were basically the same as those employed by Solomon and Moore (1975): Each animal was restrained in a Plexiglas box (Gormezano, 1966) and run in individual file drawers, each equipped with an intelligence panel containing two audio-speakers and two panel lights located behind white plastic translucent screens.

Each screen was $5 \mathrm{~cm}^{2}$. The screens were $22 \mathrm{~cm}$ apart (center to center) and $16 \mathrm{~cm}$ (center) from the floor of the file drawer. The animal's eyes were approximately $11 \mathrm{~cm}$ from the floor and $18 \mathrm{~cm}$ from the panel. Thus, each light was located approximately $35 \mathrm{deg}$ to the right or left of the longitudinal axis of the animal at the position of the eyes. The reader is referred to De Graauw and Van Hof (1978) for a discussion of the optical properties of the rabbit eye with respect to stimuli located in various parts of the visual field.

Both screens were illuminated from behind by $4.5-\mathrm{V}$ dc incandescent lamps (Chicago Miniature Type 313). Offset of either the right or left light for $\mathbf{4 0 0} \mathrm{msec}$ defined a CS. Otherwise, both lights were on for the entire session of 100 trials. There were 10 daily sessions, each with $50 \mathrm{CS}+$ and $50 \mathrm{CS}-$ presentations in a fixed random order, restricted such that no more than two trials of a given type occurred in succession. The intertrial interval was constant at $30 \mathrm{sec}$.

The unconditioned stimulus (US) on reinforced trials was a 3.0-mA ac paraorbital shock applied to the region of the right eye. It was $50 \mathrm{msec}$ in duration and terminated with $\mathrm{CS}+$ so as to define a CS-US interval of $350 \mathrm{msec}$. For half the animals, $\mathrm{CS}+$ was offset of the left-hand light and CS- was offset of the right-hand light. These contingencies were reversed for the other half. Offset of the right-hand light was CS+ for three of nine hippocampals, two of five neodecortical controls, and five of six nonoperated controls.

A continuous white masking noise of $75 \mathrm{~dB}$ SPL was on throughout the experiment. Conditioned responses were defined as $1-\mathrm{mm}$ deflections of the oscillographic recording pen as transduced by an electromechanical link to the right nictitating membrane (see Gormezano, 1966; Solomon \& Moore, 1975) and occurring within the CS-US interval.

\section{Prior Conditioning}

All subjects had been previously conditioned to a tone CS $(1,200 \mathrm{~Hz}, 75 \mathrm{~dB}$ SPL) using the same US and temporal parameters employed in differential conditioning. Both panel lights and the white noise were on throughout 2.5 daily sessions of acquisition (100 reinforced trials per session) and 2 days of extinction training (100 nonreinforced tone presentations per session). The nine hippocampals that completed differential conditioning gave an average of $75 \%$ CRs over these 250 acquisition trials and 39\% CRs in extinction. These means do not differ significantly from those of the four neodecortical controls ( $79 \%$ and $28 \%$, respectively) or from those of the six nonoperated controls $(68 \%$ and $33 \%$, respectively). Therefore, the three groups of animals appeared to be comparable in conditionability and resistance to extinction prior to differential conditioning.

\section{RESULTS}

\section{Histology}

Reconstructions of lesions for hippocampal and partial neodecortical control animals are shown in Figure 1. All hippocampals sustained bilateral destruction of the dorsal hippocampal formation. The fimbria was sectioned bilaterally in all cases. Neodecortical controls sustained ablations of overlying neocortex that approximately matched those of hippocampals.

\section{Differential Conditioning}

The development of differential conditioning for each group is depicted in Figure 2. On the average, nonoperated controls acquired a CR to light offset more rapidly than did the two operated groups, but this difference fell far short of significance by a variety of statistical tests.

From the fourth day of training on, all hippocampectomized rabbits gave more CRs to $\mathrm{CS}+$ than to CS- (sign test, $\mathrm{p}<.002)$, and on the last session, this group gave an average of $80 \%$ more CRs to $\mathrm{CS}+$ than to CS-.

For purposes of statistical comparison with the two control groups, a discrimination index was computed for each animal as follows:
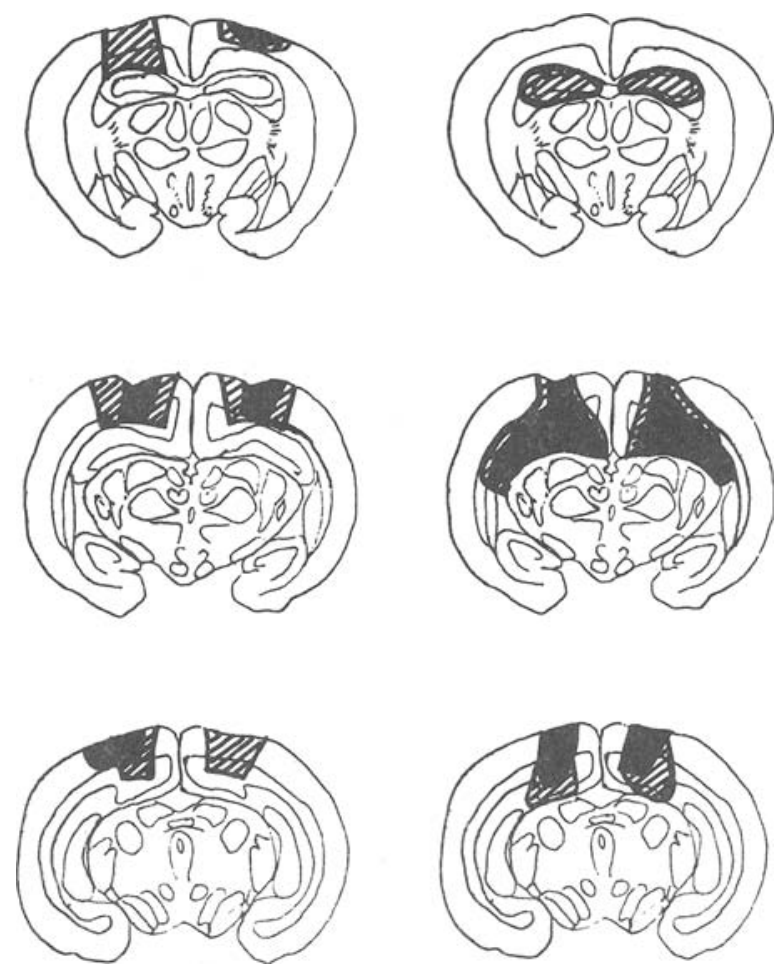

Figure 1. Reconstructions of selected transverse sections of brain showing maximum (hatched) and minimum (filled) damage for hippocampals (right) and partial neodecortical rabbits (left). 


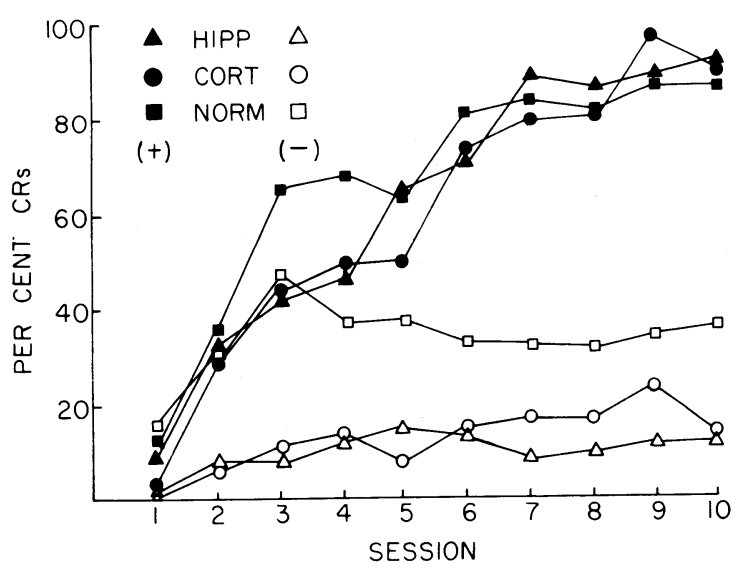

Figure 2. Mean percentage of conditioned responding to $\mathrm{CS}+$ and CS- as a function of day of training. Legend: HIPP = hippocampals; CORT $=$ partial neodecorticates; NORM $=$ nonoperated controls.

$$
\text { Index }=\frac{(\% \text { CRs to CS }+)-(\% \text { CRs to CS }-)}{(\% \text { CRs to CS }+)+(\% \text { CRs to CS }-)}
$$

For a given level of conditioned responding to $\mathrm{CS}+$, a value of 0 indicates no discrimination and a value of 1 indicates perfect discrimination.

Every trial from the beginning of training contributed to the index. Analysis of variance suggested that the three groups did not differ on this measure $[\mathrm{F}(2,17)=2.42, \mathrm{p}>.10]$, but pairwise contrasts among the three groups suggested that the difference favoring hippocampectomized rabbits over nonoperated controls may not have been due solely to chance $[\mathrm{t}(17)=2.13, \mathrm{p}<.05]$. Similar contrasts between neocortical and nonoperated controls and between hippocampectomized and neocorticals were not significant $[\mathrm{t}(17)=1.60$ and $\mathrm{t}(17)=.28$, respectively].

There was no apparent effect on performance as a function of whether offset of the right-hand or lefthand light served as CS+. Averaging over groups, the mean indices were .65 and .62 , respectively.

\section{DISCUSSION}

In apparent contradiction of cognitive map theory, rabbits with bilateral damage of the dorsal hippocampal formation were not impaired in spatial differential conditioning.

It is possible that the extent of the damage to the hippocampal formation was insufficient to produce a deficit in cognitive mapping function. More extensive destruction, including the more ventral aspects of the structure, might have resulted in a performance deficit. Nevertheless, the extent and locus of hippocampal damage in the present experiment is comparable to that known to produce deficits in latent inhibition in rabbits (Solomon \& Moore, 1975).
It is also possible that the task employed in the present experiment was not difficult enough to engage the cognitive mapping system. This possibility could be explored by increasing the difficulty of the task by, for example, reducing the visual angle between the two lights.

Finally, it is possible that a cognitive map is not essential for this task, that it might be solved by a strategy based on "egocentric" rather than extrapersonal space. The egocentric strategy would arise by comparing the relative illumination of the two eyes: For example, if the offset of the right-hand light were paired with the US, then on these occasions there would be more light flooding the left eye than the right eye. A decision rule based on which eye was receiving more illumination might permit appropriate responding.

O'Keefe and Nadel (1978) have indicated that cognitive map theory does not apply to egocentric space. In order to disprove a cognitive mapping interpretation of spatial differential conditioning, one must prove that the animal views the CSs in terms of a cognitive map rather than egocentrically. In the absence of such proof, the cognitive map theory would not make a prediction for this task. Therefore, an advocate of the cognitive map theory could interpret the results of the present experiment as evidence that the cognitive mapping system is not involved in spatial differential conditioning.

However one chooses to interpret the bearing of the present experiment on the relevance of cognitive map theory to classical conditioning, the data are consistent with previous studies of NMR conditioning. First, acquisition was not impaired by hippocampal destruction (e.g., Solomon \& Moore, 1975). Second, to the extent that suppression of CRs to CS - involved conditioned inhibitory processes, the data are in accord with Solomon's (1977) finding that hippocampal rabbits perform normally in a conditioned inhibition task in which light onset is CS+ and the same light plus a tone is CS-.

By Solomon's (1977) account, normal differential conditioning by hippocampal rabbits would be expected by virtue of the status of CS- as a "relevant" stimulus. The hippocampus is involved in "tuning out" irrelevant stimuli, that is, those not requiring attention in order that the animal behave appropriately, but it does not participate in tuning out relevant stimuli.

\section{RITIRINCES}

Berger, T. W., \& Thompson, R. F. Neuronal plasticity in the limbic system during classical conditioning of the rabbit's nictitating membrane response. 1. The hippocampus. Brain Research, 1978, 145, 323-336.

De Granuw, J. G., \& Van Hof, M. W. Relation between behavior and eye-refraction in the rabbit. Physiology \& Behavior, 1978, 21, 257-259.

Gormezano, I. Classical conditioning. In J. B. Sidowski (Ed.), 
Experimental methods and instrumentation in psychology. New York: McGraw-Hill, 1966.

Moore, J. W. Information processing in space-time by the hippocampus. Physiological Psychology, 1979, 7, 224-232.

O'KeEFE, J., \& NADEL, L. The hippocampus as a cognitive map. Oxford: Clarendon Press, 1978.

O'Keefe, J., NAdel, L., \& Willner, J. Tuning out irrelevancy? Comments on Solomon's temporal mapping view of the hippocampus. Psychological Bulletin, 1979, 86, 1280-1289.

Solomon, P. R. Role of the hippocampus in blocking and conditioned inhibition of the rabbit's nictitating membrane response. Journal of Comparative and Physiological Psychology, $1977,91,407-417$.
Solomon, P. R. Temporal versus spatial information processing theories of hippocampal function. Psychological Bulletin, 1979, 86, $1272-1279$.

Solomon, P. R., \& Moore, J. W. Latent inhibition and stimulus generalization of the classically conditioned nictitating membrane response in rabbits (Oryctolagus cuniculus) following dorsal hippocampal ablation. Journal of Comparative and Physiological Psychology, 1975, 89, 1192-1203.

(Received for publication May 1, 1980; revision accepted June 2, 1980.) 